\title{
INVESTIGATING THE FREQUENCY OF OCCUPATIONAL EXPOSURE IN DENTISTRY STUDENTS OF AHVAZ JUNDISHAPUR UNIVERSITY OF MEDICAL SCIENCES IN SOUTHWEST OF IRAN
}

\author{
ABDOLREZA GILAVAND ${ }^{1}$, MOHAMMAD SHOORIABI ${ }^{2 *}$, MEHRNOOSH MALAKOOTIAN ${ }^{3}$ \\ ${ }^{1}$ Department of Education Development Center, Ahvaz Jundishapur University of Medical Sciences, Ahvaz, Iran. ${ }^{2}$ Department of Oral \\ Medicine, School of Dentistry, Ahvaz Jundishapur University of Medical Sciences, Ahvaz, Iran. ${ }^{3}$ Department of Oral Medicine, School of \\ Dentistry, Ahvaz Jundishapur University of Medical Sciences, Ahvaz, Iran. Email: Dsshoriabii@yahoo.com
}

Received: 17 October 2017, Revised and Accepted: 17 November 2017

ABSTRACT

Objective: In spite of great developments in infection control during recent years, many problems are still seen at the level of faculties, private, and public hospitals. Therefore, this research was carried out to evaluate the frequency of occupational exposure in dentistry students of Ahvaz Jundishapur University of Medical Sciences, Southwest of Iran.

Methods: This study was conducted using a descriptive and cross-sectional method in 2016. The population of the study included all the 124 dentistry students graduated from Ahvaz Jundishapur University of Medical Sciences (AJUMS), southwest of Iran, who started their clinical education. The data were collected through a researcher-developed questionnaire and were analyzed using SPSS 22 software

Results: A total of $84(67.7 \%)$ of the participants were male and $40(23.3 \%)$ were female. Of all the participants, $54.8 \%$ of the students had no occupational exposure, $17.9 \%$ had needle stick experience, $17.9 \%$ of them had splash exposure, and $8.9 \%$ had a history of exposure to both needlestick acid and patient discharge. In the current research, no significant relationship was found between job exposure and age, gender, and marital status $(\mathrm{p}<0.05)$. However, a significant relationship was found between occupational exposure, year of admission to university, academic semester, and educational environment $(\mathrm{p}<0.05)$.

Conclusion: Given the relatively high prevalence of occupational exposure in students, the development of prevention and exposure to occupational protocols and requiring students to comply with these protocols in clinical dentistry environments is recommended.

Keywords: Occupational exposure, Dentistry students, Ahvaz, Iran.

(C) 2018 The Authors. Published by Innovare Academic Sciences Pvt Ltd. This is an open access article under the CC BY license (http://creativecommons. org/licenses/by/4. 0/) DOI: http://dx.doi.org/10.22159/ajpcr.2018.v11i2.23191

\section{INTRODUCTION}

Occupational exposure is defined as predicted contact of the skin, eyes, mucous membrane, or environmental organs with blood or other potentially infectious substances, resulting from the function of a servant during his duty [1]. In spite of great developments in infection control during recent years, many problems are still seen at the level of faculty, private, and public hospitals [2]. These are educational, medical, and dentistry centers. As dentists, students, employees, and dental patients are usually in contact with blood and oral discharges; they are highly at the exposure of infection [2,3]. Moreover, from the viewpoint of clinicians and the public people, dentistry is considered as an occupation with excessive risks including the risk of infection [5,4]. The dentistry workplace is considered to be one of the very infectious environments due to different microbial forms contamination and the type of work performed by a dentist. This situation is attributable to the nature of the work, using dentistry tools, and the contact of the dentist with the patient's oral environment [6]. The risk of hepatitis B transmission to health workers and dentists is between $2 \%$ and $30 \%$ [5]. Furthermore, the risk of hepatitis $\mathrm{C}$ infection transmission is about $1.8 \%$. Furthermore, such infection is the most serious viral hepatitis infection due to its ability in creating chronic infection in $85 \%$ of infected people $[5,7,8]$. Center for Disease Control and Prevention investigated 208 dentistry exposures (including subcutaneous, mucous membrane, and long-term skin exposure) reported between 1995 and 2001, in which 13\% were positive for HIV source which led to serum changes since $75 \%$ of the exposed people received three PEP regimens for varying times [5]. Moreover, reports suggest that more than 3 million medical employees experience occupational exposure to sharp and cutting objects annually, leading to
16,000 cases of hepatitis $C$ virus (HCV) infection, 66,000 cases of hepatitis $B$ virus (HBV) infection, and 1000 cases of HIV infection [9]. Health and medical employees, especially physicians and dentists, are at two major risks regarding the infectious diseases. First, they are at a higher risk of infectious agents than other people, and they are considered as potential vector for transmission of infectious agents to their patients [10]. Among health personnel, dentists and their patients are always at a high risk of infections transmitted through blood due to blood-borne infections and other body fluids [11]. Dentists and dental care providers similar to other health-care providers are always at a risk of occupational exposure to blood-borne pathogens such as HIV, hepatitis B, and hepatitis C $[5,4]$. In the dentistry career, injuries as a result of sharp objects occur for different reasons including small work area, continuous movement of patients, and the use of several sharp tools in dental procedures [12]. Therefore, the risk of exposure to infections transmitted through blood during dentistry clinical trainings and lack of following up of suspected cases and even infections need to be continuously evaluated by dental institutions [5]. In spite of various infectious risks caused by the clinical environment of the dentistry job, this field of study is still considered among the high-demanded fields of study among university students in Iran and many countries in the world. [13]. In addition, research suggests that students in dentistry have better mental state compared to students of other fields [14]. Furthermore, despite low risk of exposure to infections in dentistry due to protection standards, dentistry students are at high risk of exposure due to various other reasons such as their low experience and skill and non-reporting of exposures leading to inappropriate follow-up and management after exposure [15]. It can also result in physical and even mental consequences in this group of people. Given the above-mentioned argument and the importance of identifying 
the present situation for better planning to minimize the complications of this phenomenon, and as a few studies have been conducted so far in Iran regarding this phenomenon among students, the current research was carried out to evaluate the frequency of occupational exposure in dentistry students of Ahvaz Jundishapur University of Medical Sciences (AJUMS), southwest of Iran.

\section{METHODS}

This research was carried out using descriptive and cross-sectional methods prevalent in 2016. The population of the study included all M.D students (General) of dentistry working in AJUMS, who had started their clinical education. Ofall the students, 124 were selected as the sample of the study using census method. In fact, the sample of the study was considered to be equal with research population, which $67.7 \%$ of them were female and $32.3 \%$ of them were male, and most of the students $(58.1 \%)$ were aged under 25 years. The data collection tool was a researcher-developed questionnaire which was validated by and according to the views of faculty members, infectious disease specialists, and oral and dental specialists of AJUMS. Moreover, its reliability was obtained at $86 \%$ using Cronbach's alpha. This researcher-developed questionnaire included three sections. The first section contained questions on demographic characteristics of the samples such as age, gender, marital status, and educational environment. The second section of questionnaire contained questions on the rate of exposures and its frequency during the past 6 months, and the rate of infection with patient's discharges (including the history of splashing the patient's discharges on the face and other unprotected parts of the body) and its frequency. Data were collected at a specified period of time. Accordingly, after obtaining a license from the Faculty of Dentistry and Research Deputy of AJUMS, the researcher explained the research objectives and ensured the participants that the information will remain confidential. Then, the researcher collected the data. Descriptive statistics were first used to analyze the data. Following that, Chi-square test was used to examine the relationship between the variables. SPSS 22 software was also utilized in analyzing the data, and the significance level of the tests was considered at the level of 0.05 . All required ethical considerations were observed in this research and ethical code of IR.AJUMS.REC.1395.673 was issued by AJUMS.

\section{Findings}

In terms of occupational exposure, findings revealed that most of the samples (54.8\%) had no occupational exposure, $17.9 \%$ had needlestick, $8.9 \%$ had splash exposure, and $17.9 \%$ had a history of exposure to both cases of needle stick and patient's discharges (Table 1).

In addition, the data revealed that most of the participants in this research (47.2\%) experienced needlestick in several wards (Table 2).

In this research, the relationship between occupational exposure and some demographic characteristics were also investigated (Table 3), and findings, using Chi-square test, revealed that there was a significant difference between occupational exposure and gender, age group, and marital status ( $p>0.05)$. However, the rate of needlestick and splash exposure was higher in clinical educational environment of dentistry faculty in samples, and this difference was statistically significant $(p=0.000)$.

\section{DISCUSSION}

One of the main concerns in the dentistry occupation is the risk of infection transmitting from the patient to the dentist through occupational exposures including exposing to patients' discharges and injuries caused by needle or sharp objects [16-18]. In this regard, students of this field of study are always at risk of these occupational exposures due to low experience during the educational process. Results of this research considering the status of occupational exposure in the samples revealed that $17.9 \%$ of the samples had the needlestick experience, $8.9 \%$ of them had splash exposure, and $17.9 \%$ of them had a history of exposure to both needlestick and patient discharges. In this regard, various studies have been conducted in Iran and foreign countries. In a study conducted by Utomi (2006), to examine
Table 1: Frequency of exposure in samples in terms of type of exposure

\begin{tabular}{ll}
\hline Type of exposure & $\mathbf{n}(\mathbf{\%})$ \\
\hline Needle & $22(17.9)$ \\
Splash exposure & $11(8.9)$ \\
Both & $22(17.9)$ \\
No exposure & $68(55.3)$ \\
Sum & $123(100)$ \\
\hline
\end{tabular}

Table 2: Frequency of needlestick in samples in terms of ward

\begin{tabular}{ll}
\hline Ward type & n (\%) \\
\hline Diagnostic & $1(2.8)$ \\
Surgical & $2(5.6)$ \\
Other wards & $16(44.4)$ \\
Several wards & $17(47.2)$ \\
Sum & $36(100)$ \\
\hline
\end{tabular}

Table 3: Occupational exposure status in samples separately in terms of demographic characteristics

\begin{tabular}{llll}
\hline \multirow{2}{*}{$\begin{array}{l}\text { Type of } \\
\text { occupational } \\
\text { exposure }\end{array}$} & \multicolumn{2}{l}{ Type of occupational exposure } & \\
\cline { 2 - 4 } & Needlestick & Splash exposure & Both \\
\hline $\begin{array}{l}\text { Gender } \\
\quad \text { Male }\end{array}$ & $12(30.0)$ & $2(5.0)$ & $7(17.5)$ \\
$\quad \begin{array}{l}\text { Female } \\
\text { Age group }\end{array}$ & $10(12.0)$ & $9(10.8)$ & $15(18.1)$ \\
$\quad<25$ & $10(13.9)$ & $5(6.9)$ & $12(16.7)$ \\
$25-30$ & $11(24.4)$ & $5(11.1)$ & $8(17.8)$ \\
$\quad$ Higher than 30 & $1(16.7)$ & $1(16.7)$ & $2(33.3)$ \\
$\begin{array}{l}\text { Marital status } \\
\text { Single }\end{array}$ & $20(18.7)$ & $8(7.5)$ & $19(17.8)$ \\
$\quad$ Married & $2(12.5)$ & $3(18.8)$ & $3(18.8)$ \\
$\begin{array}{l}\text { Educational } \\
\text { environment }\end{array}$ & & & $21(24.1)$ \\
$\quad \begin{array}{ll}\text { Clinical } \\
\text { Paraclinic }\end{array}$ & $22(25.3)$ & $8(9.2)$ & $1(2.8)$ \\
\hline
\end{tabular}

occupational exposure and infection control in dentistry students in Nigeria, findings revealed that $50.9 \%$ of the participants had one or more occupational exposures during the past 6 months [19]. Stewardson et al. (2004) also evaluated the occupational exposure to body fluids among a group of dentistry students in the United Kingdom. They reported that $12-40 \%$ of students experienced one or more occupational exposures since the start of their educational course [16]. In addition, in a study conducted by Martins et al. (2010) in Brazil, to evaluate the prevalence and characteristics of needlestick and injuries related to sharp objects and its related factors, findings revealed that the rate of cutaneous injuries in 6 past months was 19.1\%, and it was $81.3 \%$ during the working life [17]. Furthermore, in a study conducted by Myers et al. (2012) to assess the knowledge, attitude, and the occupational exposure of dentistry students to blood-borne pathogens, findings showed that the frequency of exposure to blood-borne pathogens was $19.1 \%$ [18]. In another study by Shaghaghian et al. (2015) to assess the occupational exposure to blood and body fluids among dentistry students in Shiraz, findings revealed that $80 \%$ of students experienced occupational exposure to blood or body fluids during clinical education courses [21]. As findings of the above-mentioned studies suggest, the prevalence of occupational exposure in dentistry students is relatively high, which is in line with our findings. The results of this research also showed that most participants in the study (more than 47\%) were exposed to needlestick in several wards and splash exposure. The wards who experienced more occupational exposures were surgical and pediatric wards, which might be due to the aggressive nature of the surgical procedures and less cooperation among pediatric patients, leading to more occupational exposure of students. In similar studies, most of the 
occupational exposure of students occurred in surgical wards $[20,21]$. Finally, this research examined the relationship between occupational exposure and demographic characteristics of the samples. The results revealed differences between the occupational exposure of females and males, that is, the needlestick is higher among males and splash exposure was higher among females. However, this difference was not statistically significant. Moreover, the results indicated that occupational exposure is high at the age group of 25-30 years, but this difference was not statistically significant either. Furthermore, the findings showed that needlestick was high among single subjects and splash exposure was high among married people, yet this difference was not statistically significant. Similarly, Stewardson et al. (2002) reported that there is no significant relationship between the gender of people, the use or nonuse of gloves and daytime, and occupational exposure. However, in the current study, occupational exposure in males was slightly higher than that in females [20]. In addition, in the study conducted by Utomi (2006), no significant relationship was found between exposure level of students and their age group, and no significant relationship was reported between the level of exposure and gender [19]. In a study conducted by Shaghaghian et al. (2015), no significant relationship was found between the level of exposure and the demographic variables in dentistry students [21]. Stewardson et al. (2004) also reported no significant relationship between age, gender, dominant hand, and time of day [22]. In another study conducted by Martins et al. (2010), it was reported that occupational injuries were higher in female gender, older age, those consumed alcohol, single people, those who worked $8 \mathrm{~h}$ per day without resting, those who never used gloves, and those who always used the mask [17]. Results of the current study also revealed that needlestick and splash exposure were higher in the clinical education environment in the samples, and this difference was statistically significant. This might be due to the fact that students are more involved in clinical environments with aggressive procedures. In a research conducted by Stewardson et al. (2002), it was reported that occupational exposure was significantly lower in the past year students, and students at lower years showed higher occupational exposures, and needlestick was reported as the main injury in this group of students [21]. These results are not consistent with the results of the current study perhaps due to the different nature of the clinical education planning in different educational environments. In addition, in a research conducted by Myers et al., occupational exposure was reported higher in clinical students compared to preclinical students [18]. It is necessary for education related to occupational exposure and infection control to be included in preuniversity textbooks, so that students enter the clinical environment with higher readiness and knowledge. Research suggests that all health topics are needed to be fully included in the textbooks $[23,24]$.

\section{CONCLUSION}

Given the findings of this research, relatively high prevalence of occupational exposure in students is revealed, and considering the potential serious risks of such exposures in infections such as hepatitis and AIDS, developing prevention and occupational exposure protocols, and requiring students to observe these protocols in clinical dentistry environments are recommended.

\section{ACKNOWLEDGMENT}

This paper was extracted from a thesis written by Mehrnoosh Malakootian, and MD student of Dentistry at Ahvaz Jundishapur University of Medical Sciences, Ahvaz, Iran, Grant code: B-9560. Ethical code: IR.AJUMS.REC.1395.673

\section{AUTHORS' CONTRIBUTIONS}

The background and results are written by the first and third author. The method and discussion are written by the first author with critical methodological revision from the second author. The literature search was conducted by the econd and third author. KSF provided critical methodological revision and supervision. Both authors read and approved the manuscript.

\section{COMPETING INTERESTS}

The authors declare that they have no competing interests.

\section{REFERENCES}

1. Brewer JD, Elston DM, Vidimos AT, Rizza SA, Miller SJ. Managing sharps injuries and other occupational exposures to HIV, HBV, and HCV in the dermatology office. J Am Acad Dermatol 2017;77:946-51000000.

2. Shooriabi M, Gilavand A, Emam SA. Evaluating the participation ratio of dental assistants working in dentistry centers of the city of Ahvaz in Southwest Iran in infection control educational courses. Pharm Lett 2016;8:16-23.

3. Cleveland J, Bonito B, Corley T, Foster F, Barker L, Brown G, et al. Advancing infection control in dental care settings. J Am Dent Assoc 2012;143:1127-38.

4. Kumar S. Knowledge, attitude, and practices regarding infection control among undergraduate dental students Asian J Pharm Clin Res 2016;9:220-4.

5. Kumar S, Rahman R. Knowledge, awareness, and practices regarding biomedical waste management among undergraduate dental students Asian J Pharm Clin Res 2017;10:341-5.

6. Singh A, Purohit BM, Bhambal A, Saxena S, Singh A, Gupta A, et al. Knowledge, attitudes, and practice regarding infection control measures among dental students in central india. J Dent Educ 2011;75:421-7.

7. Younai FS. Health care-associated transmission of hepatitis B and C viruses in dental care (dentistry). Clin Liver Dis 2010;14:93-104.

8. Sofola OO, Folayan MO, Denloye OO, Okeigbemen SA. Occupational exposure to blood borne pathogens and management of exposure incidents in Nigerian dental schools. J Dent Educ 2007;71:832-7.

9. Elseviers MM, Arias-Guillén M, Gorke A, Arens HJ. Sharps injuries amongst healthcare workers: Review of incidence, transmissions and costs. J Ren Care 2014;40:150-6.

10. Yanuar A, Syahdi RR, Aryati WD. Parameter optimization and virtual screening Indonesian herbal database as human immunodeficiency virus-1 integrase inhibitor using autodock and vina. Int J Appl Pharm 2016;9:90-3.

11. Babu C, Devanna N, Reddy KS. Validated gradient stability indicating rp-hplc method for the simultaneous quantification of 11 related substances in the combined dosage forms of lamivudine and tenofovir disopeoxil fumarate. Int J Appl Pharm 2016;9:61-8.

12. Younai FS. Health care-associated transmission of hepatitis B and C viruses in dental care (dentistry). Clin Liver Dis 2010;14:93-104.

13. Gilavand A. The comparison of Iranian and foreign students' motivations to choose dentistry field of study. Int J Pediatr 2016;4:1993-2010.

14. Gilavand A. The comparison of the tuition-paid and free tuition dental students' incentives in choosing their feld of study at Ahvaz Jundishapur University of Medical Sciences, Southwest of Iran. Ann Trop Med Public Health 2017;10:1254-9.

15. Chopra SS, Pandey SS. Occupational hazards among dental surgeons. Med J Armed Forces India 2007;63:23-5.

16. Stewardson DA, Burke FJ, Elkhazindar MM, McHugh ES, Mellor AC, Coulter WA, et al. The incidence of occupational exposures among students in four UK dental schools. Int Dent J 2004;54:26-32.

17. Martins AM, Santos NC, de Lima MÉ, Pereira RD, Ferreira RC. Needlestick and sharp instrument injuries among dentists in Montes Claros, Brazil. Arq Odontol 2010;46:127-35.

18. Myers JE, Myers R, Wheat ME, Yin MT. Dental students and blood borne pathogens: Occupational exposures, knowledge, and attitudes. J Dent Educ 2012;76:479-86

19. Utomi IL. Occupational exposures and infection control among students in Nigerian dental schools. Odontostomatol Trop 2006;29:35-40.

20. Stewardson DA, Palenik CJ, McHugh ES, Burke FJ. Occupational exposures occurring in students in a UK dental school. Eur J Dent Educ 2002;6:104-13.

21. Shaghaghian S, Golkari A, Pardis S, Rezayi A. Occupational exposure of shiraz dental students to patients' blood and body fluid. J Dent (Shiraz) 2015;16:206-13

22. Stewardson DA, Palenik CJ, McHugh ES, Burke FJ. Occupational exposures occurring in students in a UK dental school. Eur J Dent Educ 2002;6:104-13.

23. Gilavand A, Moosavi A, Gilavand M, Moosavi Z. Content analysis of the science textbooks of Iranian junior high school course in terms of the components of health education. Int J Pediatr 2016;4:4057-69.

24. Shooriabi M, Gilavand A, Yazan M. Studying the necessity for presenting the science of determining the tooth shade course in educational curriculum in dentistry faculties based on the evaluation of the amount of knowledge and performance of general dentists. Pharm Lett 2016;8:298-304. 